\title{
Bernard Hamon, George Sand et Michel de Bour-ges, Une passion... 1835-1837 «Moi, je te poursuivrai jusqu'au fond de la mer...»
}

\section{Lise Sabourin}

\section{(2) OpenEdition Journals}

Édition électronique

URL : http://journals.openedition.org/studifrancesi/6036

DOI : 10.4000/studifrancesi.6036

ISSN : 2427-5856

Éditeur

Rosenberg \& Sellier

\section{Édition imprimée}

Date de publication : 1 mai 2011

Pagination : 194-195

ISSN : 0039-2944

\section{Référence électronique}

Lise Sabourin, «Bernard Hamon, George Sand et Michel de Bour-ges, Une passion... 1835-1837 «Moi, je te poursuivrai jusqu'au fond de la mer...»», Studi Francesi [En ligne], 163 (LV | I) | 2011, mis en ligne le 30 novembre 2015, consulté le 13 janvier 2021. URL : http://journals.openedition.org/studifrancesi/6036 ; DOI : https://doi.org/10.4000/studifrancesi.6036

Ce document a été généré automatiquement le 13 janvier 2021.

\section{cc) (†) $\odot$}

Studi Francesi è distribuita con Licenza Creative Commons Attribuzione - Non commerciale - Non opere derivate 4.0 Internazionale. 


\title{
Bernard Hamon, George Sand et Michel de Bour-ges, Une passion... 1835-1837 «Moi, je te poursuivrai jusqu'au fond de la mer...»
}

\author{
Lise Sabourin
}

\section{RÉFÉRENCE}

BERNARD HAMON, George Sand et Michel de Bour-ges, Une passion... 1835-1837 «Moi,je te poursuivrai jusqu'au fond de la mer...», Vendoeuvres, Lancosme éditeur, 2009, pp. 232.

1 Poursuivant sa publication de lettres par correspondants sandiens (voir notre recension de George Sand et le prince Napoléon. Histoire d'une amitié, 2008, in "Studi francesi», $n^{\circ} 159$, p. 650), Bernard Hamon propose cette fois les 57 missives conservées de George à Michel de Bourges, d'avril 1835 à octobre 1837. On sait que leurs copies originelles, collationnées par le vicomte Spelberch de Lovenjoul, puis publiées à la «Revue illustrée» en 1890-1891 sous le titre Lettres de femme, ont connu des altérations de précaution décryptées par Georges Lubin pour sa Correspondance (aux t. III et IV, confirmées et enrichies par les corrections apportées au t. XXV). Deux nouvelles lettres de l'avocat outre celle déjà connue, deux de Sand à des tiers concernant cette liaison s'ajoutent à ce dossier essentiellement daté de la fin de cette passion qui nous montre une George Sand un peu exceptionnelle, prête à se soumettre pour sauver son amour, moins maîtresse d'elle-même dans ses affections.

2 Louis Michel, né d'un charbonnier et muletier républicain massacré sept mois avant sa naissance par des royalistes, dans une Provence livrée à une lutte sauvage entre patriotes et contre-révolutionnaires, connaît une enfance difficile. Mais son intelligence, vite remarquée par le curé de Pourrières, puis par un ami qui le fait entrer au pensionnat du Tholonet, lui permet de s'établir à Aix en vivant de leçons et d'y 
suivre les audiences du Palais de Justice. Convaincu de l'inutilité de ses démarches pour faire punir les assassins de son père, il s'engage dans la Légion du Var, emporte l'acquittement d'un déserteur devant le Conseil de guerre et part obtenir à Paris son diplôme d'avocat. Lors des troubles consécutifs à l'assassinat du duc de Berry et des manifestations contestant la modification de la loi électorale en juin 1820, il se fait remarquer des services de police. Après un pamphlet sur un «rapt de séduction» d'éducation catholique sur une jeune protestante, signé Michel du Var, celui que Thiers son compatriote provençal dénomme alors le «Bridaine de la Révolution» suit finalement son ami Brisson pour s'inscrire au barreau de Bourges qui lui confère le nom que l'histoire a retenu.

3 Son talent atypique d'orateur, employant la déduction philosophique au service de la loi, dédaignant la petite guerre de procédure au profit d'une sobre agressivité, lui assure la notoriété dans «Le Journal du Cher» et un mariage bourgeois avec une riche veuve en 1827. À la tête du mouvement libéral berrichon, il combat le gouvernement né des journées de juillet 1830 et brille en défendant des citoyens républicains devant la cour d'assises de la Seine en 1831. Candidat malheureux à la députation, il entre totalement dans l'opposition après l'insurrection de juin 1832, multipliant les plaidoiries en faveur de vignerons luttant contre leurs impositions. Élu bâtonnier de Bourges, il intervient dans les grands procès d'assises à Paris comme en Berry: ainsi estil sollicité en 1835 par George Sand pour défendre les insurgés de Lyon.

4 Au terme de l'aventure vénitienne avec Musset, l'écrivain est désormais convaincue de la précarité de ses traités avec son mari: elle décide donc de consulter aussi le célèbre avocat pour obtenir en justice la séparation totale. La rencontre est un éblouissement réciproque et donne aussitôt naissance à une correspondance suivie. Les amants se rencontrent durant l'été dans des «maisons désertes», sans doute appartenant aux Déséglise à Bourges, brouillant les pistes avant un automne pénible: pour George, altercation avec Casimir Dudevant en présence de leurs amis à Nohant; purgation d'une peine de prison à Bourges pour républicanisme de Michel. La séparation prononcée et la gestion de ses biens reconnue, George peut désormais se livrer à sa passion plus librement, mais Michel, que la prudence conjugale pousse à des atermoiements, lui fait maints reproches, notamment concernant sa fréquentation de Charles Didier, l'écrivain suisse connu par sa Rome souterraine. Au fil des allées et venues, de Bourges à Nohant, de Paris à Genève chez Liszt et Marie d'Agoult, les missives se chargent d'exaltation et de tourment, laissant libre cours à des protestations passionnées comme au dépit amoureux. La rupture éclatera finalement à la fin de l'été 1837, non sans laisser grand éclairage sur les œuvres conçues durant ces mois: Simon qui présente un net portrait de l'âme inquiète de Michel (voir p. 39), Mauprat dont l'Edmée présente le type de femme forte sachant façonner l'homme aimé qu'elle aurait rêvé d'incarner auprès de lui, les modifications apportées à la seconde Lélia à la lumière de la liberté chèrement acquise. Mais c'est encore la sixième Lettre d'un Voyageur qui nous présente le mieux sa relation à Everard, dont certaines lettres pleines de poésie (voir p. 87, par exemple) constituent des prémices évidents. 